\title{
Economics as social engineering? Questioning the performativity thesis
}

\author{
Ana C. Santos and João Rodrigues ${ }^{\star}$
}

\begin{abstract}
The social engineering ambitions of economics have never been so high. Economists are increasingly invited to construct markets from scratch or to design mechanisms that mimic the market. Science students take these social engineering efforts as evidence for the capacity of economists to make the economy more like its description in economic theories. This paper scrutinises one such viewpoint. It examines Michel Callon's performativity thesis that presents the stronger stance regarding the impact of economics on the economy-economic theory can be made true by construction. It concludes that the research carried out thus far fails to support this thesis. It has shown that economics, understood in a very loose sense, has an active role in market building.
\end{abstract}

Key words: Auctions, Experiments, Market mechanisms, Performativity FEL classifications: A11, C90, Z13

\section{Introduction}

The engineering ambitions of economics have never been so high. Economists increasingly praise and promise an engineering economics. Science students take the recent engineering efforts of economics as evidence for the capacity of economists to make the economy more like its description in economic theories. Michel Callon goes so far as to claim that economics 'performs, shapes and formats the economy, rather than observing how it functions' (1998A, p. 2). The performative power of economics is such that 'the economy is embedded not in society but in economics' (1998A, p. 30).

Having as its foundational landmark the book edited by Callon, The Laws of the Markets (1998B), the performativity programme is still very much in its infancy. It has, however, inspired many case-studies that investigate the causal impact of economics in the economy.

Manuscript received 18 March 2008; final version received 29 October 2008.

Address for correspondence: Ana C. Santos, CES, Centre for Social Studies, School of Economics, University of Coimbra, Colégio S. Jerónimo, Apartado 3087, 3001-401 Coimbra, Portugal; email: anacsantos@ces.uc. pt; joao.rodrigues@postgrad.manchester.ac.uk

* University of Coimbra, Portugal and University of Manchester. Ana C. Santos (SFRH/BPD/28966/ 2006) and João Rodrigues (SFRH/BD/38310/2007) acknowledge the financial support of the Fundação para a Ciência e Tecnologia. We thank José Maria Castro Caldas, Ben Fine, Fred Lee, Uskali Mäki and two anonymous referees for the critiques and suggestions that significantly improved this article. We also want to thank the participants at the 12th World Congress of the Association for Social Economics and at the 2007 Annual Conference of the European Association for Evolutionary Political Economy, where earlier versions of this article were presented. All errors and omissions are the authors' own making.

(C) The Author 2009. Published by Oxford University Press on behalf of the Cambridge Political Economy Society. All rights reserved. 
And it proposes a particular approach to this effect. It replaces the traditional conception of science as a descriptive form of knowledge by one that conceives of economics as a set of instruments and practices that act upon economic players and economic institutions. The traditional dichotomies conveyed by the notions of representing and intervening, science and policy, and academic inquiry and political intervention are judged inadequate to depict the relation between science and society. Economic theories, models, instruments and practices act upon the economy while being used to observe, measure, predict, explain or regulate its workings. And this explains why the economy increasingly acts in accordance with economic theories. In sum, the use of economics in the economic processes affects how resources are produced, organised, exchanged and consumed.

The performativity of economics is a general thesis about the effect of economics on the economy, which may include any item of economics - a theory, a model, a procedure, a data-set, etc. But Callon has focused on the analysis of the deliberate and planned creation of new markets and of the creatures that inhabit them-homo economicus. And so will we. We will examine a market building endeavour that has attracted a great deal of attention-the spectrum auctions launched in 1994 by the US Federal Communications Commission (FCC). These auctions have been taken as one of the most successful cases of economic engineering and an exemplary case of economics performativity. Even though the FCC auctions can be associated with the creation of a market, which mobilised game theory and economics experiments among other resources and professionals, the view that they constitute an instance of performativity, as Callon presents it, is disputed.

In a lively debate held in the European Electronic Newsletter, Economic Sociology, NikKhah argued that 'the evidence does not support the widespread impression ... that economists' game theoretic accounts of auction theory dictated the format of the auctions adopted, and therefore rendered the economists' theories "true" by construction' (2006, p. 15). Guala, by contrast, claimed that 'experimental and theoretical considerations did play a role declaring one solution [the simultaneous-multi-round-independent auction] superior to its main competitor [the combinatorial auction]' (2006, p. 25), concluding that 'the performativity approach is left untouched by Nik-Khah's story' (2006, p. 26). At the same time, Guala conceded that his and Nik-Khah's accounts were largely complementary and that the appraisal of the FCC auctions was still to be made by 'scientific argument'.

We will argue that the controversy around the implications of the FCC auctions for the performativity thesis is not so much a result of the lack of scientific argument as it is symptomatic of the ambiguity surrounding the concept of performativity.

The paper is structured as follows. Section 2 presents the performativity thesis as put forward by Callon. In Section 3, two different notions of performativity are identified. The strong notion of performativity asserts that the engineering efforts of economists make economics true by construction. The weak sense of performativity makes the more tenable assertion that the participation of economics in market building contributes to the commodification of social life and assists economic agents in their calculations. Section 4 shows that while the strong notion is too demanding, rendering the performativity of economics a rather rare phenomenon, the weak notion risks triviality because it may accommodate virtually any instance of market building. Analysis of FCC auctions shows that the auctions do not constitute an instance of performativity in the strong sense. The auctions did not render auction theory, or any other theory, true by construction in any meaningful way. But neither do the FCC auctions constitute a telling case of performativity in the weaker sense. We then conclude that Callon promises more than he can actually deliver. While insisting on the bold claim that economists can enact the reality 
described in their theories, Callon is often forced to retreat to the more moderate, if not trivial, assertion that economics, understood in a very loose sense, has an active role in the creation of markets.

\section{The performativity of neoclassical economics and market engineering ${ }^{1}$}

The performativity programme stresses the fact that economics is 'performative'. This means that through the careful and purposeful design of socio-economic institutions of a market-like nature economists succeed in enacting the patterns of behaviour postulated or predicted by economic theories. And it highlights two interconnected elements: the theoretical statements that describe behavioural patterns (singular existential statements in Callon's terms) and the socio-economic institutions that create the conditions for their enactment (sociotechnical agencements in Callon's terms) (2007).

The theoretical statements and the socio-economic institutions are intrinsically interrelated. The events the statements describe cannot be dissociated from the context denoted by and built into the statement. Theoretical statements are propositions of the kind 'at such-and-such a place, and at such-and-such a time, and under such-and-such circumstances such-and-such behavioural pattern can be observed'. By describing events and the circumstances in which they occur, theoretical statements evoke more or less explicitly the socio-economic institutions that bring about the described events. The socioeconomic institutions are man-made arrangements of heterogeneous elements that include 'human bodies but also .... prostheses, technical devices, algorithms, etc.', which are carefully adjusted to one another so as to bring about the events described by the statements (Callon, 2005, p. 4). And this is not a trivial achievement; it 'is realized only after a long collective effort, which one could call economic research, involving 90 percent engineering and 10 percent theory' (Callon, 2007, p. 333). In Callon's view, the critical feature of these man-made arrangements is their capacity to act and give meaning to action.

The performativity thesis therefore endorses a particular understanding of individual and collective human action, which is largely dependent upon the structural configurations of the arrangements and the networks in which human action takes place. ${ }^{2}$ The implication of this is that the patterns socio-economic institutions bring about disclose, first and foremost, the nature of arrangements that configure agents' actions, rather than stable behavioural traits of human beings based on an allegedly unchanging human nature (Callon, 1998B, 2005, 2007).

The socio-economic institutions are therefore at the core of the performativity programme. They bridge the gulf separating the theoretical statements produced by academic economists (or confined economists, to use an expression favoured by Callon) and the economy; and they do this when they bring about the events described by economic theories. It is in this way that the statements of economics become true by construction or come to describe and represent their worlds correctly. The implication of this, in Callon's view, is that the relevant criterion to assess economics is success, rather than truth, where success is measured by the extent to which reality conforms to what is described by economic theories. But, Callon notes, success is bound to be a temporary achievement. The performativity of economics eventually has to come to grips with overflowings, i.e. reactive responses to the worlds created by economists.

\footnotetext{
1 Unless explicitly stated otherwise, references given in Sections 2 and 3 refer to Callon.

2 This perspective is reminiscent of Callon's previous work within the actor-network theory (ANT) that aimed at surpassing the dualism of agency and structure (see Fine 2003, 2005).
} 
Even though it is stated in broad terms, and can be applied to various items of economics, the performativity thesis places neoclassical economics in the foreground. This is not surprising given the tremendous influence of neoclassical economics in the academic and in policy-making circles. Indeed, this branch of economics is the hegemonic conceptual framework of those involved in concrete processes of market construction. Callon then focuses on neoclassical economic theory with its inbuilt commitment to a particular view of human agency, prevailing human motivations, behaviours and forms of rationality. Inspired by neoclassical economics, the creation of markets then brings about a 'calculative agency', i.e. 'a self-interested agency obsessed by the calculation-optimization of his or her own interest' (Callon, 2007, p. 346). Thus, and notwithstanding the explicit recognition of the inevitable variability and specificity of markets, Callon has a particular conception of the market and of the calculative rationality prevalent therein. Thus, the performativity of economics ultimately amounts to the production of the 'calculative agencies' postulated by neoclassical economic theory, that is, homo economicus.

While reproducing the idealised versions of neoclassical economic man, Callon at the same time offers his particular version of it. The 'neoclassical anthropological program', as Callon calls it, is characterised by (i) the disentanglement of things and humans, (ii) the centrality of individual human agencies, and (iii) the underplay of the uneven distribution of calculative equipment and capacities among agencies (Callon, 2007, p. 343).

First, Callon takes the performativity of economics to produce 'disentanglements' between commodities and the agents who produce and trade them. Even though Callon takes these disentanglements as a direct consequence of the participation of neoclassical economics in market building, the separation of objects and subjects of market transactions is one of the unavoidable elements of any commodification process. Market transactions presuppose the definition and guarantee of property rights and the monetisation of human interactions, which break the ties between goods and people. This separation stems, as Castree remarks, from the fact that the 'commodity status of a thing, object, idea, creature, person or what-have-you is not intrinsic to it, but rather assigned' (Castree, 2003, p. 277). The set of property rights is crucial to sustain and assure the alienability of the object, i.e. the physical and/or moral separation from its owner, the seller, on a formally volunteer basis, as when the buyer and the seller agree on its monetary value. Money, in turn, makes commensurable that which was not so before and thereby allows the construction of a common scale of equivalence for the various market goods. The implication of this is that rather than being the direct cause of disentanglements, the performativity of economics is part of the general process of commodification, which requires precise actions to cut the ties between humans and the goods that become marketable.

Second, Callon takes the performativity of neoclassical economics to produce 'calculative agencies'. The use of the neoclassical market as a model in market building favours the creation of special conditions for economic agents to execute their calculations in the pursuit of their individual interests. Callon takes the study of Garcia-Parpet (2007 [1986]) as an illustration of this. ${ }^{1}$ The strawberry auction, created in 1981 in

\footnotetext{
${ }^{1}$ Callon takes this study as an exemplary case of performativity, in the sense that it produced the 'neoclassical anthropological program'. The author, Garcia-Parpet, takes this study as an illustration of an approximate implementation of the theoretical model of perfect competition. In the ideal model of perfect competition: (i) agents are price-takers, (ii) the goods are homogeneous, (iii) there is perfect mobility of factors and there are no obstacles to enter or exit the market and (iv) perfect knowledge of goods and prices is assured.
} 
Fontaines-en-Sologne, France, is used to show how the creation of a new market replaced personal relationships with the impersonal exchange of a commodity, and how the material devices designed for the operation of the market assisted in the calculation of individual interests. But Callon notes that 'the crucial point is not that of the intrinsic competencies of the agent but that of the equipment and devices (material: the warehouse, the batches displayed side by side; metrological: the meter; and procedural: degressive bidding) which give his or her actions a shape' (1998A, p. 21).

Homo economicus needs a specific environment to flourish and support material collective devices. These devices, created with the help of neoclassical economics, assist individuals in making the calculations that the theory presumes they are capable of doing autonomously. From this it follows that homo economicus can only be true by construction: ' $[\mathrm{I}] \mathrm{f}$ he exists he is obviously not be found in a natural state . . He is formatted, framed and equipped with prostheses which help him in his calculations and which are, for the most part, produced by economics' (Callon, 1998A, p. 51). Therefore, from the fact that they perform calculations in rarefied market environments, one cannot infer that individuals are calculative beings. And neither can it be assumed that individuals are egoistic and asocial human beings. Nonetheless, Callon retains the ideal of maximising and optimising behaviour. $\mathrm{He}$ does so, despite the engineering efforts to create conditions for the emergence of the 'calculative agencies' he describes.

Just as it is difficult to attribute the separation of things and humans to neoclassical economics, it is equally difficult to assess the role of neoclassical economics in the production of calculative agencies. The emergence of calculative agencies might be simply the result of the commodification of social life, associated with the processes of market expansion. Moreover, the new calculations individuals make in the market may take many forms. As Slater notes, 'the fundamental defining feature of a market is a kind of transaction rather than a purified form of calculation. The essential market transaction is the "alienation" of goods in the form of property, which entails limits on the kind of social relationship formed between transactors' (2002, p. 235).

Indeed, the study of MacKenzie and Millo (2003) shows that not even in the most clearcut case of the performativity of economics did economic agents become homo economicus. In the derivative financial markets 'they might have priced options as economic theory said they should, but they never became morally atomistic' (p. 139). This is so because markets never ceased to be moral communities in which social norms and values such as reciprocity, generosity and reputation also have their part. MacKenzie and Millo conclude: 'With the aid of economic theory, of technology, and of much else, a passable version of homo economicus can be and has been configured cognitively, so to speak. Whether he can be configured morally, out of real men and women, remains an open question' (2003, p. 140). MacKenzie and Millo therefore touch on the tension between a nuanced and more open view of performativity and the univocal association of the performative capacities of economics with the notion of homo economicus.

Callon eventually concedes that '[a] total, unambiguous configuration is impossible'. $\mathrm{He}$ clarifies that every market is the product of different, sometimes antagonistic, performative programmes, contributing to the existence of mutually interwoven calculative and noncalculative moral agencies. As a result, Callon includes in the performativity research agenda the study of how 'the anthropology of economics is constantly confronted with other, equally performative, anthropological programs' (2007, p. 347). But, as we shall see, he insists on keeping homo economicus in the foreground. 
Although Callon does not devote as much attention to the third characteristic of the 'neoclassical anthropological programme', the performativity of economics is considered a political process which is carried out by 'dominant economic agents designing and imposing modalities of encountering' (Callon, 2007, p. 349). The performativity of economics therefore carries the potential to ignore or aggravate the asymmetries expressed by this different distribution of political power. But the market remains a highly plastic and malleable institution. It is still prone to multiple reconfigurations, since there will always be overflowings as a result of the unavoidable effects of agents' actions upon one another. These reconfigurations may then give rise to struggles that aim at imposing new rules capable of internalising these effects as is frequently the case in disputes about negative externalities such as pollution.

\section{The strong and the weak senses of performativity}

Callon makes the bold claim that economics is performative because the engineering efforts of economists succeed in producing the reality described in economic theory. Economists do so by designing particular socio-economic institutions of a market-like nature that produce the patterns of behaviour postulated or predicted by economic theories. In particular, and this is the strongest sense in which economics can be said to be performative, economists can produce, through their engineering efforts, the 'calculative agencies' postulated by neoclassical economic theory, that is, homo economicus.

On closer scrutiny, a much weaker sense of performativity can also be identified in Callon's writings. In this more lenient notion, economics is performative whenever it is used in market building and thereby contributes to the commodification of social life and assists economic agents in calculating their interests in those particular circumstances. This is a less stringent condition, in that it suffices that economics is in some way engaged in the construction of markets and in assisting economic calculations.

Both the strong and the weak notions evoke the creation of markets. But whereas the strong notion entails the emergence of 'a self-interested agency obsessed by the calculation-optimization of his or her own interest' (Callon, 2007, p. 346), the weak version refers to the more tenable conception of the 'neoclassical anthropological program' associated with the commodification of social life and the replacement of personal relationships with impersonal exchange and the introduction of new forms of calculation (Callon, 2007, p. 343).

The performativity of economics may come in different degrees, as various authors have noted (e.g. MacKenzie, 2006). ${ }^{1}$ It can conceivably be expected that the performative efficacy of the uses of economics in the economy varies. It may depend, for instance, on which items are used and for which purposes. To be sure, we agree that economics can be performative in different ways and to different degrees. But we find the strong notion too demanding. Moreover, we take issue with Callon's misuse of the weak notion to make the bold claim that economics can be made true by construction. By taking the mere construction of markets as an instance of performativity in the strong sense, Callon

\footnotetext{
${ }^{1}$ Mackenzie (2006) offers a classification of various versions of the thesis according to their different degrees of realisation. While 'generic' performativity refers to the mere use of an item of economics (a theory, model, concept, procedure, etc.) in economic practice, 'effective' performativity only comprises the subset of cases in which the use of economics 'makes a difference'. If this use of economics makes economic processes more like their depiction, we have an instance of 'Barnesian' performativity; but if this use makes economic processes less like their depiction by economics, we have instead an instance of 'counterperformativity'.
} 
misleadingly conveys the idea that any process of market building produces homo economicus and implicitly generates market efficiency. ${ }^{1}$

A substantial number of empirical case-studies already supplies varied illustrations of economics' performativity. The seminal study by Garcia-Parpet (2007 [1986]), which describes the implementation of a market, deemed to be an instance of the theoretical model of perfect competition, marked the beginning of a growing interest in auctions and, particularly, in auctions sponsored by public institutions. The FCC auctions to be reviewed below are most eloquent in showing the intricacy of interaction between academic economists, policy-makers and businessmen in market design. The recent studies by MacKenzie and Millo (2003) and MacKenzie (2006) of the financial derivative markets constitute another important addition to the field. And many other studies have been made that have already given rise to a book published on the topic (MacKenzie et al., 2007).

MacKenzie and Millo's analysis of the role of option pricing theory in legitimising and actually facilitating, at least for a period, the development of financial derivative markets have, however, drawn attention to some of the limits of Callon's thesis. Even though MacKenzie and Millo convincingly argue that the Black-Scholes-Merton model succeeded in bringing about a state of affairs of which it was a good description, this emerges as an exceptional case:

While one can be reasonably sure that the generic performativity and effective performativity of economics are widespread, matters are not so clear in respect to Barnesian performativity and counterperformativity, which may be rare and hard to identify unequivocally. What is probably unusual about the case of option theory (one cannot be entirely sure about its frequency until far more empirical work is done) is the existence of a single, stable, canonical form of the theory: the Black-Scholes-Merton model (Mackenzie, 2006, p. 51). ${ }^{2}$

Even though these studies and the debate they brought about have forced Callon to integrate further amendments and qualifications, which indicate that a much weaker understanding of performativity is the tenable option, Callon still insists on making the strong claim.

This ambiguity is present, for instance, in Callon's reading of Holm's study (2007) of the reorganisation of the Norwegian fishing industry, which consisted of introducing quotas to limit the capture of fish stocks and of new devices to control, measure and detect fishery. Indeed, Callon bluntly takes this study as an illustration of the performativity of economics in the strongest sense, since he claims that economics participated 'in the actualization of a world in which it becomes or is true' (Callon, 2007, p. 337). But Callon does not say which part of economics became true by construction. Callon simply states that the market reconfigurations transformed 'the dark and mysterious ocean into a transparent aquarium' and the 'Norwegian fisherpeople into homines economici'. And this seems to be the case, according to Callon, because 'without economics the market would not exist' and 'the fishermen's calculative and maximizing rationality cannot be investigated as long as this market does not exist' (Callon, 2007, pp. 337-8).

Granted that the introduction of the quotas substantially changed the Norwegian fishing industry as well as the calculations of fishermen, who became quota owners, no evidence is given for the transformation of fishermen into calculative and rational maximisers. It is

\footnotetext{
${ }^{1}$ In other words, while Callon wants to make the case for a 'Barnesian' kind of performativity, he uses evidence of the generic kind to support Barnesian performativity (cf. note 1, p. 6 of this article).

${ }^{2}$ See note 1, p. 6 of this article, for Mackenzie's definitions of performativity.
} 
simply assumed that the market reconfiguration by transforming fishermen into quota owners also turned them into rational men. ${ }^{1}$ Callon therefore seems to fall prey to circular reasoning. He takes the participation of economics in the particular reconfiguration of this market as evidence for the instantiation of homo economicus. But the attribution of new propriety rights to the fisherman does not in itself generate the pure calculative and maximising agencies that are presupposed by neoclassical economic theory. Nonetheless, it might be reasonable to expect that this market reconfiguration furthered 'disentanglements' of humans and things and altered calculations. But this is the much weaker and almost trivial sense of performativity.

Indeed, market building can conceivably produce 'disentanglements' in various ways and independently from economic theory. This is evident given, if for no other reason, that markets and associated disentanglements predate economics. When considering that Callon endorses a broad conception of economics - which encompasses all the resources that participate 'in the construction of a world described and performed by statements and models that we readily agree belong to the world of economics' and also '[a] host of professions, competencies, and non-humans [which] are necessary for academic economics to be successful' (Callon, 2007, p. 332) - then any process of market building becomes, by definition, an instantiation of economics. Thus, while the strong notion is too demanding, rendering the performativity of economics a rather exotic endeavour, the weaker notion, which is equally pervasive in Callon's account, is trivially true.

A critical problem of the performativity programme, as Fine $(2003,2005)$ noted, is that it lacks a theoretical framework that discerns the mechanisms at play, both at the micro level of individuals' behaviour and at the macro level of the 'logic' of the market economy and its main institutions. Such a framework would be critical to account for the relation between the material and the ideological processes and the participation of economics in shaping each one of them and their mutual relation. Without this, Fine argues, 'the idea that economists constitute markets is simply a tautology or an assertion of causation without supporting argument' (2003, p. 480). Callon thus fails to demonstrate that the economy 'is embedded not in society but in economics', both empirically and theoretically. Callon simply assumes that markets produce the effects that economic theories predict they do, without providing any explanatory mechanism that can account for those effects.

The performativity programme has been subject to other kinds of criticism. Miller (2002), for example, goes so far as to claim that the performativity programme is simply indefensible. Contra Callon, Miller claims that the behavioural assumptions of neoclassical economists cannot become true. Economic relations are unavoidably embedded in, and saturated by, cultural and moral 'entanglements', which make neoclassical economics views necessarily untenable descriptions of economic life. He then argues that what ends by being 'within the frame is not the market as an actual practice, but on the contrary a ritualized expression of an ideology of the market', i.e. 'a moral and ideological system whose intention is to create the normative conditions for exchange rather than a description of practice' (Miller, 2002, p. 224, emphasis in original).

\footnotetext{
${ }^{1}$ It should be noted that Callon follows closely and uncritically Holm's version of the case-study: 'Now, the fisherman, being a quota owner (and rational lest you forget) must consider this: will I make more money by fishing myself, or selling the quota to someone else? If the market works according to theory-and why wouldn't it? - the quota will flow to the most efficient fisherman, since he, everything else equal, will be able to pay the best price' (Holm, 2007, p. 236).
} 
The positions of Callon and Miller are not necessarily incompatible. While mainstream economics can conceivably propose a utopian endeavour, in the double sense that the word acquired in Polanyi's (1957) analysis of the viability of 'market society'-it never existed and it is very difficult for anyone to imagine a society where it could exist-it nevertheless has a variable capacity to influence the way people think and behave. This influence, following Ferraro et al. (2005), may be exercised via two channels: (i) the direct role that the popularised versions of economic theory have in the creation of a new common sense in shaping the language used and the social norms invoked by individuals, and (ii) the influence that theory has in conducting of public policy and in institutional design and the ways in which these mould people's patterns of behaviour.

Nevertheless, and to return to the critique made by Fine, more work has to be done to clarify the links between commodification processes and their theoretical elaborations. For this to be possible, one should be open to the possibility that not only economic discourses influence the particular configurations that markets might assume, but also that the social relations produced by these configurations can account for the emergence and dominance of certain discourses and ways of interpreting the world. In the end, it might be rather consensual that economic theory influences individuals' values and behaviour, and that it does so through the diffusion of certain institutional arrangements. But this is not the line of inquiry to be pursued here. We will focus instead on the FCC auctions to argue that this successful story of economics engineering does not count as an exemplary case of the performativity of economics, neither in the strong nor in its weak version.

\section{The FCC auctions and the performativity of economics}

The FCC auctions have been announced as the biggest engineering success of economics and, naturally, they have been selected to illustrate the performativity of economics. But the studies made so far on these auctions do not support Callon's strong notion of performativity (Guala, 2001, 2006; Mirowski and Nik-Khah, 2007; Nik-Khah, 2006, 2008). Even though FCC auctions succeeded in building a market for selling licenses, and this process benefited from the contributions of game theorists and experimental economists, among other resources and professionals, they cannot count as an instance of making economics true by construction in any meaningful way. Nor do they unambiguously fit the weaker notion of performativity conveyed by the neoclassical anthropological programme, as Callon defines it.

In 1993, the US congress charged the FCC with the design of an auction mechanism which would allocate licenses to use the electromagnetic spectrum for personal communication systems. The FCC subsequently decided to call for academic game theorists to participate in the policy-making process. This call also gave interested parties the idea of hiring game theorists as consultants. Game theorists then participated in the process of market building as consultants for both the institutional regulator, to assist in the design of the auction, and the telecommunication companies who needed advice to help them obtain the most desirable licenses (Nik-Khah, 2006, 2008).

In 1994, the FCC implemented what was to be known as the simultaneous-multipleround-independent auction, which would soon be praised as 'the greatest auction in history' (McAfee and McMillan, 1996, p. 159). This auction launched a market for thousands of spectrum licenses in which most US telecommunication firms in the telephone and cable-television business participated. Its success in raising billions of dollars for the public treasury has been taken as evidence for the practical usefulness of 
game theory. The FCC auction is deemed to have supplied 'a case study in the use of economic theory in public policy' (McMillan et al., 1997, p. 429), which constituted 'a triumph, not only for the FCC and the taxpayers, but also for game theory (and game theorists)' (Fortune in McAfee and McMillan, 1996, p.159).

According to the official version, as recounted by the game theorists themselves, the auctions aimed at creating a transparent and an efficient market that would allocate the airwave spectrum rights to the highest value users-those who most valued and made best use of them. ${ }^{1}$ Until 1982, spectrum licenses were assigned by an administrative hearing process (recognisably slow and non-transparent), which allocated licenses for free. After 1982, licenses were sold and allocated via a lottery system that significantly improved the speed and transparency of the allocation mechanism. But it did not prevent opportunistic behaviour. Licenses could be bought and resold by individuals who did not want to use them, and thus undeservedly appropriated revenue raised with the commercial use of the public spectrum.

The auction mechanism, then, seemed to offer a tremendous advantage over the alternatives. It offered the possibility of identifying the firms with the highest use-values for the spectrum, which would be in the position of paying the highest prices for using it and, as a result, maximise the FCC's revenue. This in turn required the design of an auction mechanism that encouraged bidders to reveal their true valuations while preventing opportunistic behaviour on their part.

Game theorists took the credit for building the FCC auctions. However, as we shall see, it involved other resources and participants. The game theorists plainly acknowledged that ' $[\mathrm{t}]$ he spectrum sale is more complicated than anything in auction theory. No theorem exists - or can be expected to develop - that specifies the optimum auction form'. The reason for this was that ' $[\mathrm{m}]$ ost of the existing theory omitted the crucial feature of the spectrum auction: the fact that the licenses complemented and substitute for each other' (McAfee and McMillan, 1996, p. 171-2).

Because the auction designs raised important practical questions for which theory had no answers, the building of the FCC auctions was a complex endeavour, best depicted as a patchwork of various and partial solutions to the particular issues that arise when building new markets. The auction design resembled 'a kind of engineering activity', which had recourse to all sorts of resources ranging from 'practical judgments, guided by theory and all available evidence' to 'ad hoc methods to resolve issues about which theory is silent' (Milgrom, 2000, p. 271). In this regard, game theory's major contribution consisted of 'developing intuition', in particular 'to show how people behave in various circumstances and to identify the tradeoffs involved in altering those circumstances' (McAfee and McMillan, 1996, p. 171).

The auction design had to tackle three major technical issues. First, to ensure that the highest-value users bought and paid for the licenses at their value; second, to allow the composition of favoured combinations of licenses, which had to take into account licenses' complementarities and substitutability and, third, to prevent opportunistic behaviour on the part of bidders, which would jeopardise the competitive gains obtained from instituting the market. Theory would help in looking at the strategic structure of the decision-making

\footnotetext{
1 This account is based on game theorists' reports of the events after efficiency had been set as the main goal of the auction in detriment of other welfare goals defined by the congress, such as the expansion of public access to new technologies, products and services, and the decentralisation of the licenses awarded to include small businesses, rural telephone companies, and minority groups. For a more complete account of the political process involving the FCC auctions see Nik-Khah (2008).
} 


\section{Questioning the performativity thesis}

problem and anticipate 'how bidders choose their bids, not knowing the value of the item for sale and not knowing what their rivals know; and what the seller can do to stimulate the bidding competition, not knowing how much any of the bidders is willing to pay' (McMillan, 1994, p. 146).

Based on advice from the game theorists, the FCC opted for the simultaneous-multipleround-independent auction that gave bidders the possibility of operating in several markets at the same time and thus of composing desirable aggregations of items or adjusting their aggregation to a last-resort composition if their first-choice aggregations became unattainable. The licenses would then be allocated to the highest bidder that paid his/her bid price. This auction was also considered more capable of dealing with the freerider problem that was more likely to occur in the alternative auction considered-the combinatorial auction. ${ }^{1}$

Many detailed rules were devised to avoid the opportunistic exploiting of any gap. For example, an activity rule required the payment of deposits on the total number of desired licenses at the beginning of the auction to ensure that market participants actually intended to own and use the licenses. Given the high stakes in evidence, the government was also concerned with simplifying procedures, in order to reduce the incidence of mistakes. To avoid the 'winners' curse', i.e. selling of licenses to traders who overestimated their value (cf. Kagel and Levin, 1986), or to avoid the extra cautionary behaviour of risk-averse bidders, the bids were announced at every round so that traders could make better estimates of the licenses' values. The incidence of unpredictable mistakes was further taken into account by allowing bid withdrawal, though with a penalty.

The next step then consisted of gluing together these partial solutions to evaluate whether they could be implemented in an operational environment. To this end,

[j] udgment and guesswork were needed to merge the various partial theories, to weigh the government's various objectives, to estimate the relative sizes of the different effects, and to evaluate whether a proposed scheme was workable. Laboratory experiments also were used to test whether people bid as theory predicts, and to look for hidden gaps in the rules that might leave the auction open to manipulation by the bidders. (McMillan, 1994, p. 151)

Game theorists gave the impression that laboratory experiments were used to test the relative magnitude of conflicting effects and work out the gaps left by theory. But experimental economists did more than that. They were crucial in actually putting the various pieces together into a workable mechanism and solving the complications that emerged while trying to do so (Guala, 2001; Nik-Khah, 2006, 2008). The building of the FCC auctions however, followed, a division of labour in which the game theorists proposed the auction form and the rules that would organise the functioning of the market, and the experimental economists implemented these rules in an electronic market.

After stabilising the auction rules, the experimenters subsequently tested the auction under conditions that closely resembled the market to be implemented. Only then were experimenters able to assess the combined effect of the auction's rules, which could not possibly be predicted by non-experimental means. Because the data collected from the laboratory were similar in many relevant aspects (e.g. bidding patterns, price trajectory, license aggregations, etc.) to the data obtained from the FCC auctions, the experimenters were confident that the auction goals had also been achieved therein (Guala, 2001).

\footnotetext{
${ }^{1}$ Game theorists argued that by selling aggregations instead of single licenses, the combinatorial auction would not take advantage of the competitive bidding that would ensue from the sale of single items.
} 
Even though the accounts of the economists involved in auction design make us believe otherwise, the success story of the FCC auctions has been contested. In an evaluation of the results, Cramton (1998, p. 735) states that 'any auction would look good relative to the FCC's past experience with comparative hearings and lotteries'. At the same time, he concedes that 'it is impossible to say exactly how efficient the auctions were' and retreats to the more vague claim that the auctions were successful for the government and for the bidders (p. 728). Nik-Khah, based on the archives of the FCC, tells a more pessimistic story, which is worth quoting at length:

It is demonstrably false that the spectrum auctions satisfied the congressional goals. Many businesses buying licenses defaulted on their down payments (Murray, 2002: 274-275), leading to considerable 'administrative delay' in re-awarding licenses. The lion's share of licenses won by 'small' and 'entrepreneurial' businesses went to entities bankrolled by large telecoms, representing a failure to get licenses into the hands of a 'wide variety of applicants'. The auctions have not lived up to their promise to promote 'rapid deployment [in] rural areas', as both large telecoms and smaller firms have tended to concentrate their effort on large metropolitan areas (Copps, 2004; Meister, 1999: 76-77). Overall, the allocation of licenses produced by the auctions proved to be unstable, as the industry has gone through a spate of mergers, acquisitions, and bankruptcies, ultimately leading to a high degree of license concentration (Murray, 2002: 289-291). Commenting on some of these events, one anonymous FCC official candidly observed, 'this certainly does make us look like a bunch of idiots' (Labaton and Romero, 2001). True, the auctions did capture a tidy sum for the government coffersmore, anyhow, than 'beauty contests' or lotteries would - but perhaps they did so at the expense of any solid foundations for the economic health of the industry over the medium term. (Nik-Khah, 2008, p. 90, footnotes omitted)

The process of market design culminating in the implementation of the simultaneousmultiple-round-independent auction was a complex endeavour that mobilised heterogeneous resources. It mobilised two conflicting theoretical contributions: auction theory and Walrasian general-equilibrium theory. ${ }^{1}$ It benefited from experience with other attempts at building auctions for the sale of spectrum licenses. It involved judgement and guesswork about how the various bits of the auction were to be put together. And it also included the participation of the various interests in confrontation.

Game theorists were eager to wrap their contribution in the allure of science, emphasising that 'the auction design process was driven not by politics, but by economics' (McMillan, 1994, p. 147). But, as Nik-Khah shows, the process of building the auction was marked by the interests of the constituencies in presence, namely those of the telecommunication corporations. Large corporations hired game theorists to help them to position themselves in the policy-making process, first by lobbying for the most favourable architectures for the auctions and then by assisting defining their clients' bidding strategies. As Charles Plott, one prominent consultant, acknowledge: 'Business understood that the rules and form of the auction could influence who acquired what and how much was paid' (1997, p. 606).

Because game theory was unable to provide a conclusive argument for the choice of a specific auction form, Nik-Khah concluded that 'firms' narrowly constituted interests clearly played a major role' (2008, p. 82). For Guala, however, 'experimental and theoretical considerations did play a role in declaring one solution superior to its main competitor' (2006, p. 25). Possibly both economics and the interests of the telecoms contributed to the choice of the simultaneous-multiple-round-independent auction. What evidence does not show, however, is that the auctions constitute an instance of

\footnotetext{
${ }^{1}$ See Nik-Khah $(2006,2008)$ for a detailed comparison between these two research programmes and their respective contribution to the building of the FCC auctions.
} 
performativity in the strong sense. They did not render auction theory, or any other theory for that matter, true by construction in any meaningful way.

For one thing, and as we have seen, the auction design is the outcome of a patchwork of various solutions that makes it increasingly hard to evaluate the partial contribution of each one of them. This is indeed recognised by Callon. He takes the FCC auction as an illustration of co-performativity of two alternative programmes where 'none of the protagonists is able to push his or her own program through to the end, for none of them is able to completely frame the world that they create'. As result, 'they can only adopt a logic of compromise in which some elements of their world are realised and others are not' (Callon, 2007, p. 341). While experimental economists had to accept the solution proposed by game theorists (i.e. the auction form), experimental economists also introduced elements of their own world by imposing technical solutions drawn from experimentation.

Even though Callon acknowledges that the final design 'was a patchwork, cobbled together with elements from competing worlds', he does not derive any particular conclusion for his performativity programme. The various elements in the end constructed a world in which they could work: 'whether they state a formula, build a piece of software, or devise an accounting technique, they all give themselves a world or worlds so that the formula, model, or software that they put into circulation (utter) finds an environment, agencements, enabling it to function' (Callon, 2007, p. 341). Even if we accept that the various bits and pieces of economics used in the FCC auction played the role Callon attributes to them, this does not seem to constitute an interesting and meaningful case of performativity.

For the FCC auction to count as an instance of performativity in the strong senseunderstood as the capacity 'to make the world that it describes, and that makes it true, exist' - it would have to generate outcomes predicted or described by any of the theories involved in its production. But that there were no such theories available, or discovered in the process, is what explains the nature of the engineering process that we have just described. Not even the more elusive goal endorsed by game theorists of allocating the licenses to the highest-value users seems to have been accomplished. The bankruptcies, the court battles, and the after-trade that followed indicate this (cf. Nik-Khah, 2008). That various bits and pieces of economics participated in the design of the FCC auction is not what Callon wants to convey by the strong, or weak, senses of performativity.

In the end Callon is only able to sustain the milder claim that game theory succeeded in instantiating the neoclassical anthropological programme: 'The GTs [game theorists] won the battle and pushed the disentanglement process a step forward, deploying the market world further and further. Without economics (that of GTs) this deployment would have been simply unimaginable' (Callon, 2007, p. 344). Callon is here reproducing the same reasoning he applied to the Norwegian fishing case: because game theorists were able to determine the choice of the auction form, game theory promoted the separation of things and humans as well as human calculability, and therefore the FCC auctions constitute a case of the performativity of economics. Even though the FCC auctions created a market for selling the licenses, previously allocated via a lottery system, it is not at all clear how the FCC auctions operated further disentanglements of things and humans. The introduction of the auction simply changed the allocation mechanism. Nor does it seem to be the case that the auctions produced or enhanced the calculative skills of the telecoms. It can reasonably be expected that the telecommunication companies were already guided by their interests and that they already had the resources to pursue them. Indeed, in the face of the reconfiguration of the allocation mechanism, the large corporations did more than 
simply play the game as best they could within the given set of rules. They attempted to influence the design of the rules of the game to their advantage. And the regulator was aware of this and tried to control opportunistic behaviour, as explained above.

The possibility of controlling the actions of market participants is crucial for the success of economic engineering. Otherwise, the economic engineer will fail to bring about the intended outcomes. The FCC auctions show that this control must also be exercised beyond the borders of the market. The flaws of the FCC auctions indicate that the regulator was vulnerable to the influence of big companies during the design process and trade. It was not capable of preventing collusion and other anti-trust strategies either inside or outside the market. ${ }^{1}$ As a result, the market became more concentrated in the hands of a few large corporations.

From the foregoing analysis, it does not follow that game theory is useless for policymaking or that economic science is unimportant for social engineering. Nor does it mean that the performativity thesis should be rejected. But it means that the performativity research agenda needs to be reoriented and the case-studies need to have better-defined concepts. Callon's definitions of performativity are either too demanding or too trivial. The strong notion renders the performativity of economics either a rare phenomenon (e.g. the creation of homo economicus) or a rather circumscribed phenomenon that applies only to the bits and pieces of economics (e.g. bidding rules of an auction mechanism). The weak notion (e.g. the neoclassical anthropological programme) is too lenient and cannot be easily disentangled from the processes of the commodification of social life. More importantly, the causal efficacy of economic theories cannot be taken for granted. The interest remains, however, in examining the mechanisms through which economic engineering inspired by economics produces changes in human behaviour in line with the model of rational economic man.

\section{Conclusion}

Callon's performativity thesis conveys two different notions of performativity that are meant to apply to the recent engineering efforts of economists in market building. Whereas the strong notion asserts that economic theories can become true by construction, the weak notion makes the milder claim that economics is actively engaged in market building.

We have seen, however, that market engineering is a complex endeavour whose final outcome is often unpredictable. It requires paying special attention to the details of the market to be implemented and dealing with unanticipated complications. To that end, it mobilises various heterogeneous resources and recruits professionals with varied and often conflicting worldviews. It relies on well-established resources, tacit knowledge, as well as on informed intuition. Because it destabilises the balance of the interests in presence, market building is also a process of constant negotiation and compromise in the collective effort to work out the various cognitive, technical and political problems that emerge when attempting to design an operational market. This is why it is so difficult to demonstrate a strong instance of the performativity of a given economic theory. Market building frames and shapes the interactions of individuals for the attainment of rather elusive goals, say the allocation of resources in an operational way, while attempting to curb opportunistic behaviour on their part.

${ }^{1}$ This is expressively conveyed by Paul Milgrom's announcement on CNN Business Morning, which attempted to deter bidding on licenses Pacific Bell had targeted. He said: 'Pacific [bell] expects to win licenses in California. We expect the other bidders to have opportunity to become discouraged when they see how determined we are' (transcript in Nik-Khah, 2008, pp. 90-1). 


\section{Questioning the performativity thesis}

The case-studies reviewed here have also shown that the engineering efforts of economists cannot make homo economicus true by construction. Economic agents do not become morally atomistic and calculative human machines in markets. Markets never cease being moral communities in which social norms and values also have their part. The weak sense of performativity may, however, occur in any process of creation of new markets. This is the case because the performativity of economics in the weaker sense simply amounts to the process of market expansion, which, by definition, promotes disentanglements between 'humans and things' and favours some kind of self-interested form of reasoning.

All things considered, one could be led to conclude that the performativity project has failed and that it has nothing going for it. We suggest, however, a reformulation of its research agenda. Rather than taking as a starting point the assertion that economics can shape reality in its own image and then reconstruct economic reality so as to fit this pressuposition, a more fruitful research agenda would consist of identifing the mechanisms through which economics participates and shapes social life. And there is an urgent need for this kind of understanding given the engineering prospects of economics.

These prospects have already inspired Alvin Roth (2002), an influential game theorist, to launch Design Economics as the engineering field of economics. The ambition is to bring together the contributions of game theory, experimental and computational economics to the design of allocation mechanisms that mimic the properties of the market. These aim to solve various kinds of allocation problems, such as the allocation of jobs and of human organs. This project is already underway. Private and public entities have more and more recourse to the consultancy services of economic engineers, who are also becoming successful businessmen.

The recent engineering turn in economics is promoting a widespread belief in the technical capability of economists to devise market-like mechanisms to solve various kinds of socio-economic problems. As a result, it is also promoting, a favourable discourse on the need to circumvent the social resistances encountered when wanting to introduce monetised exchanges where they were not previously present. Ideas about the inappropriateness of certain kinds of transaction can indeed constitute serious obstacles to market design, as is the case with gifts and in-kind exchanges that become repugnant when money is added to the transaction. The challenge, from the engineering point of view, is, then, to learn how to circumvent these moral constraints, increasingly perceived as part of a technical problem that needs to be tackled (cf. Roth, 2006).

Critical reactions to the performativity thesis suggest that the obstacles encountered are not external interferences that only need to be identified in order to be removed. These interferences arise because human beings are necessarily entangled in social networks and communities. The analysis carried out here therefore recommends including the identification of these resistances in the new research agenda of the performativity programme. Rather than trying to fit reality into the framework of neoclassical economics, this agenda should instead be devoted to the examination of the consequences of the attempts at making reality conform to economic theories.

\section{Bibliography}

Callon, M. 1998A. Introduction: the embeddedness of economic markets in economics, pp. 157 in Callon, M. (ed.), The Laws of the Markets, New York, Blackwell Publishers

Callon, M. (ed.), 1998B. The Laws of the Markets, New York, Blackwell Publishers 
Callon, M. 2005. Why Virtualism Paves the way to Political Impotence-A Reply to Daniel Miller's Critique of The Law of the Markets, Economic Sociology-European Electronic Newsletter, vol. 6 , no. $2,3-20$

Callon, M. 2007. What Does it Mean to Say that Economics is Performative? pp. $311-57$ in MacKenzie, D., Muniesa, F., and Siu, L. (eds), Do Economists Make Markets? On the Performativity of Economics, Princeton, Princeton University Press

Castree, N. 2003. Commodifying what nature? Progress in Human Geography, vol. 27, no. 3, 273-97

Cramton, P. 1998. The Efficiency of the FCC Spectrum Auctions, Fournal of Law and Economics, vol. $41,727-36$

Ferraro, F., Pfeffer, J. and Sutton, R. 2005. Economics and Language Assumptions: How Theories Become Self-Fulfilling, Academy of Management Review, vol. 30, 8-24

Fine, B. 2003. Callonistics: a disentanglement, Economy and Society, vol. 32, no. 3, 478-84

Fine, B. 2005. From Actor Network Theory to Political Economy, Capitalism Nature Socialism, vol. $16,91-108$

Garcia-Parpet, M. 2007 [1986]. The Social Construction of a Perfect Market: The Strawberry Auction at Fontaines-en-Sologne, pp. 20-53 in MacKenzie, D., Muniesa, F., and Siu, L. (eds), Do Economists Make Markets? On the Performativity of Economics, Princeton, Princeton University Press

Guala, F. 2001. Building Economic Machines: The FCC Auctions, Studies in History and Philosophy of Science, vol. 32, 453-77

Guala, F. 2006. Getting the FCC Auctions Straight: A Reply to Nik-Khah, Economic Sociology-European Electronic Newsletter, vol. 7, no. 2, 23-8

Holm, P. 2007. Which way is Up on Callon? pp. 225-43 in MacKenzie, D., Muniesa, F., and Siu, L. (eds), Do Economists Make Markets? On the Performativity of Economics, Princeton, Princeton University Press

Kagel, J. and Levin, D. 1986. The Winner's Curse and Public Information in Common Value Auctions, American Economic Review, vol. 76, 894-920

MacKenzie, D. 2006. Is Economics Performative? Option Theory and the Construction of Derivative Markets, Fournal of the History of Economic Thought, vol. 28, no. 1, 29-55

MacKenzie, D. and Millo, Y. 2003. Constructing a Market, Performing Theory: The Historical Sociology of a Financial Derivatives Exchange, American fournal of Sociology, vol. 109, 107-45

MacKenzie, D., Muniesa, F., and Siu, L. (eds), 2007. Do Economists Make Markets? On the Performativity of Economics, Princeton, Princeton University Press

McAfee, R. P. and McMillan, J. 1996. Analysing the Airwaves Auction, fournal of Economic Perspectives, vol. 10, 159-75

McMillan, J. 1994. Selling Spectrum Rights, Fournal of Economic Perspectives, vol. 8, no. 3, 145-62

McMillan, J., Rothschild, M. and Wilson, R. 1997. Introduction, fournal of Economics and Management Strategy, vol. 6, 425-30

Milgrom, P. 2000. Putting Auction Theory to Work: The Simultaneous Ascending Auction, Fournal of Political Economy, vol. 108, no.2, 245-72

Miller, D. 2002. Turning Callon the right way up, Economy and Society, vol. 31, no. 2, 218-33

Mirowski, P. and Nik-Khah, E. 2007. Markets Made Flesh: Performativity, and a Problem of Science Studies, Augmented with Consideration of the FCC Auctions, pp. 190-224 in MacKenzie, D., Muniesa, F., and Siu, L. (eds), Do Economists Make Markets? On the Performativity of Economics, Princeton, Princeton University Press

Nik-Khah, E. 2006. What the FCC Auctions can tell us about the performativity thesis, Economic Sociology-European Electronic Newsletter, vol. 7, no. 2, 15-21

Nik-Khah, E. 2008. A Tale of Two Auctions, Fournal of Institutional Economics, vol. 4, no. 1, 73-97

Plott, C. 1997. Laboratory Experimental Testbeds: Application to the PCS Auction, fournal of Economics and Management Strategy, vol. 6, 605-38

Polanyi, K. 1957. The Great Transformation, Boston, Beacon Press

Roth, A. E. 2002. The Economist as Engineer: game theory, experimentation, and computation as tools for Design Economics, Econometrica, vol. 70, 1341-78

Roth, A. E. 2006. 'Repugnance as a Constraint on Markets', NBER working paper no. 12702

Slater, D. 2002. From calculation to alienation: disentangling economic abstractions, Economy and Society, vol. 31, no. 2, 234-49 